\title{
EXPERIMENTAL TESTS OF FLUID EXCHANGE PROCESS IMPROVEMENT IN A NEW DESIGN OF HYDRAULIC CYLINDER WITH A SUPPLY SYSTEM
}

\author{
Tomasz Siwulski ${ }^{1 *}$, Urszula Warzyńska $^{1}$, Marcin Rys² ${ }^{2}$ Maciej Skrzypczak ${ }^{2}$ \\ ${ }^{I}$ Wroctaw University of Science and Technology, Faculty of Mechanical Engineering, Lukasiewicza 5, 50-371 \\ Wrocław, Poland \\ ${ }^{2}$ HYDROMAR, Powstańców Wlkp. 57a, 64-500 Szamotuly, Poland \\ * Corresponding author: Tel.: +48 713202892; E-mail address: tomasz.siwulski@pwr.edu.pl
}

\begin{abstract}
The article presents the results of experimental tests of the liquid exchange level in a new design of a hydraulic cylinder in comparison with the classic one. Comparative results are presented, as well as the influence of the stroke range on the degree of liquid exchange. The results allow the empirical determination of the degree of real improvement of the process of liquid exchange in the cylinder during operation, and thus allow the initial determination of the reliability level increase in hydraulic cylinders. It should be emphasized that the presented results are a part of a research and implementation project carried out in cooperation between a university and an industrial partner. In addition, the presented test method of hydraulic cylinders is, in the opinion of the authors, an interesting proposition, which can be used by manufacturers of this type of components in the world.
\end{abstract}

Keywords: hydraulic cylinder, fluid exchange process, experimental tests

\section{INTRODUCTION}

Hydraulic systems for working machines have been developed by Wroclaw University of Science and Technology in cooperation with industrial partners in three main areas. The first research area covers issues related to the influence of static and dynamic forces which are generated during the operation of working systems and which act on hydraulic power systems, with particular emphasis being placed on the phenomena observed in machine boom systems. The second research area is the analysis of pressure pulsations generated when working systems are operated, with primary focus on variable external loads. In the third research area, the aim is to improve the reliability and life of the individual elements of hydraulic systems operated under high ambient temperature conditions. This article presents the results of work performed within the third research area. The article also describes all of the works performed as part of the research and development project, which started from identifying the technical problem and ended with the introduction to the market of a new solution comprising an integrated hydraulic cylinder with a redesigned power supply system.

\section{BACKGROUND}

The analysis of maintenance reports on selfpropelled mining machines operated in Polish deep underground copper mines in the LegnicaGłogów Copper Belt showed that the most failure-prone element of the hydraulic systems are their cylinders [1]. Defects of hydraulic cylinders typically caused the machine to be out of service for the period required to replace the damaged elements with new parts. The damage of hydraulic cylinders typically occurred in their sealing elements (Figure 1). The result was a significant increase in internal and external leakages, followed by a substantial drop in their efficiency. Visual inspection of the damaged cylinders revealed that they regularly suffered from thermal degradation of the sealing materials. In effect, the material lost its elastic properties and no longer allowed proper functioning of the cylinder sealings. The loss of tightness in turn allowed external impurities to collect inside the cylinder and entailed 
mechanical degradation of the moving surfaces of the piston, the piston rod and the cylinder. At this degradation stage, the cylinders were typically replaced.

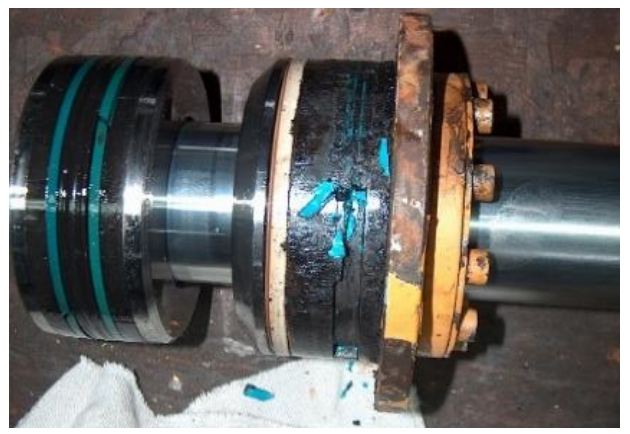

Figure 1: Sealing of the hydraulic cylinder, whose material became brittle due to high temperature

\section{PROBLEM ANALYSIS}

\subsection{Liquid exchange model}

Both in the literature and in actual engineering calculations of hydrostatic systems, an assumption is made that liquid temperature in the whole system is constant $[2,3]$. This assumption is safe in the case when the liquid circulation in the system is complete. However, in a situation when during the operation of the system some liquid volume moves in a certain area of the system and does not return to the tank, this assumption is not entirely valid. An example of such a case is a hydraulic cylinder in which the piston serves as a barrier preventing liquid flow between the chambers. During the operation of the cylinder, the liquid from the chambers is first removed into supply lines, and is further pumped to valves which regulate the flow. The liquid volume which is transferred beyond the control valve returns to the main liquid circulation line in the system and is typically removed to the tank. However, the liquid which does not flow through the control valve when the chamber is emptied will be redirected back when the chamber is filled again. Therefore, it seems justified to conclude that some part of the liquid in the classic solution is never returned to the tank and instead remains in the cylinder and hydraulic power supply lines. In effect, this phenomenon may lead to a significant liquid temperature variation, as observed for example in mining machines. In this case, the temperature values measured on hydraulic cylinders were higher than the temperature values of the liquid circulating in the system and measured with the use of a temperature transducer located in the hydraulic oil tank. For further analysis of this phenomena, in Figure 2 the schematic of a hydraulic cylinder is shown with the description of parameters, to which will refer equations and plots in the article.

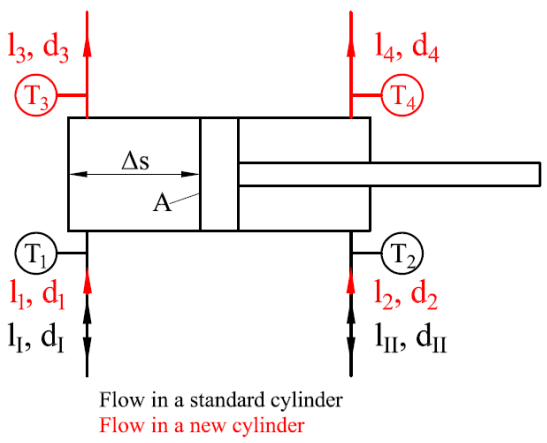

Figure 2: Schematic representation of the system comprising a cylinder and hydraulic power supply lines in the classic and the new solution

The following relationship describes the volume of liquid present in the cylinder chamber at a time of initiating a movement during which the liquid is removed from the chamber and outside of the cylinder - supply lines system $\mathrm{V}_{\mathrm{o}}$ :

$\mathrm{V}_{\mathrm{o}}=\left\{\begin{array}{c}0 \text { for } \mathrm{V}_{\mathrm{l}} \geq \mathrm{V}_{\mathrm{c}} \\ \mathrm{V}_{\mathrm{c}}-\mathrm{V}_{1} \text { for } \mathrm{V}_{1}<\mathrm{V}_{\mathrm{c}}\end{array}\right.$

The equation includes the volume of the cylinder chamber supply line $V_{1}$ and the initial volume of the cylinder chamber $\mathrm{V}_{\mathrm{c}}$. As can be seen, in the case when, as a result of the piston movement, the volume of liquid removed from the cylinder chamber is smaller than the volume of the power supply line, no part of this volume is removed outside the system. If, however, the volume of liquid removed is greater than the volume of the power supply line, only the part of liquid originally present in the cylinder chamber will be removed outside the system, while the remaining part not leave the supply line. The volumes of the presented cylinder chamber and of the power supply lines may be calculated from basic relationships:

$V_{c}=\Delta s \cdot A$ 
$V_{l}=l \cdot \frac{\pi d^{2}}{4}$

The analysis of the above relationships proved that when the cylinder is operated some liquid volume is not exchanged and never leaves the cylinder - supply lines system. As a result, it may have a significantly different temperature than the liquid which flows through the system and is returned to the tank. Moreover, this liquid does not undergo the purification process in filters, and the impurities in it are not removed from the system and continuously affect the cylinder sealings.

\subsection{New design of the hydraulic power supply system}

Initial identification of the problem enabled works on a modified cylinder supply system. Based on the above relationships, it may be concluded that in order to reduce the volume of liquid remaining in the cylinder - supply lines system, the lines should be of possibly limited length and diameter. However, such limitations are not always desired from the perspective of efficiency and machine construction. They additionally do not ensure full liquid exchange, as some liquid volume never leaves the system. Therefore, a new system was designed in which each of the cylinder chambers has two nozzles with a specified flow direction. (Figure 3).

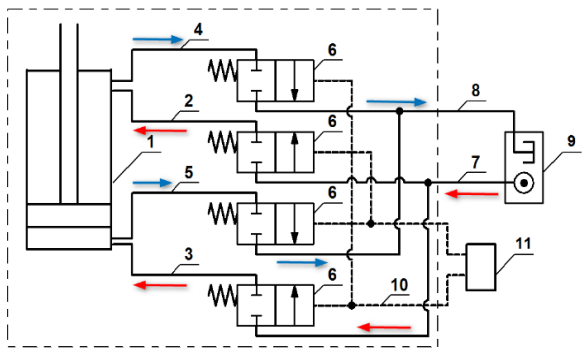

Figure 3: Schematic diagram of a new cylinder design together with a system for liquid exchange in the chambers $[4,5]$

Each of the two cylinder working chambers (1) is connected with two hydraulic lines having a defined and unchangeable flow direction. In the described system, the cylinder power supply lines (2 and 3) are only able to supply liquid to the chambers, while the return lines (4 and 5) allow liquid removal. The flow is regulated by valves
(6), actuated in pairs by control signals (10) received from the control system (11). The system was designed so that only two hydraulic lines with a specified and unchangeable flow direction are connected with the hydraulic power supply unit (9), i.e. one line is the supply line (7) and the other is the return line (8). It is advantageous to provide the valve system in a block mounted directly on the hydraulic cylinder, as the system is thus connected to the power supply with only two hydraulic lines, in a manner analogical to that in a classic doubleacting cylinder. Additionally, the hydraulic lines between the cylinder chambers and the control valves have minimized length and are made in the valve block, which makes them practically resistant to damage during operation. This solution was implemented in a prototype cylinder (Figure 4) which was then subjected to a series of tests in a specially designed test stand.

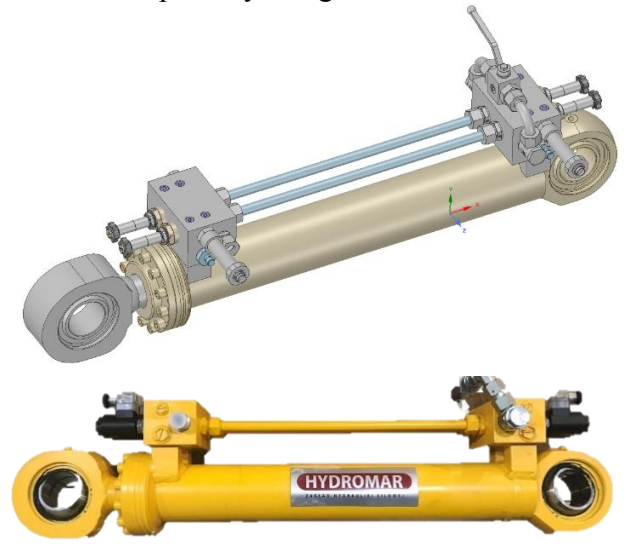

Figure 4: The 3D geometrical model and the prototype version of the new hydraulic cylinder

It should be emphasized that in the application the valves mounted on the cylinder will perform the control functions. In connection with the above, it will become superfluous to install an additional directional valve controlling the operation of the cylinder. In the newly created architecture of the system, it is foreseen to mount only the valve enabling cutting off the liquid supply to the cylinder, whose function will be related to the safety of use of the system. As a result, the preliminary assumption was made that the efficiency of the systems with classic cylinder power supply architecture and with the new 
architecture, which is the result of using the solution and its advantages, is comparable. As a result of the application of the described solution, it was possible to supply each chamber of the cylinder independently and in any configuration without the need to expand the system with an additional directional valve responsible for e.g. fast movement of the cylinder or enabling its free movement under the influence of external forces.

\subsection{Test stand and test procedure}

The test stand, developed as part of the presented research and development works, allows both durability tests and investigations into thermal and dynamic phenomena involved in the operation of hydraulic cylinders (Figure 5). It is equipped with a complete set of sensors for measuring pressure, temperature, axial forces on the piston rod and piston extension in real time. At the same time, its design enables simulations of a broad spectrum of loads on the tested cylinders, in both dynamic and static conditions.

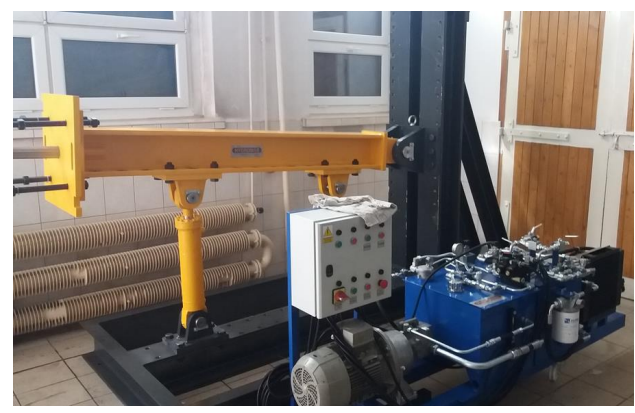

Figure 5: Test stand for testing hydraulic cylinders

Additionally, the implemented system is capable of providing any number of repeated piston extension and retraction cycles, based on the preset limit positions. This article presents the results of comparative tests performed for cylinders equipped with the new and the classic fluid supply systems. The tests were performed for several preset cylinder displacements, while the presented results are for a test series in which the piston stroke cycle was between positions located at an equal distance from the middle of the cylinder's total stroke length. (Figure 6).
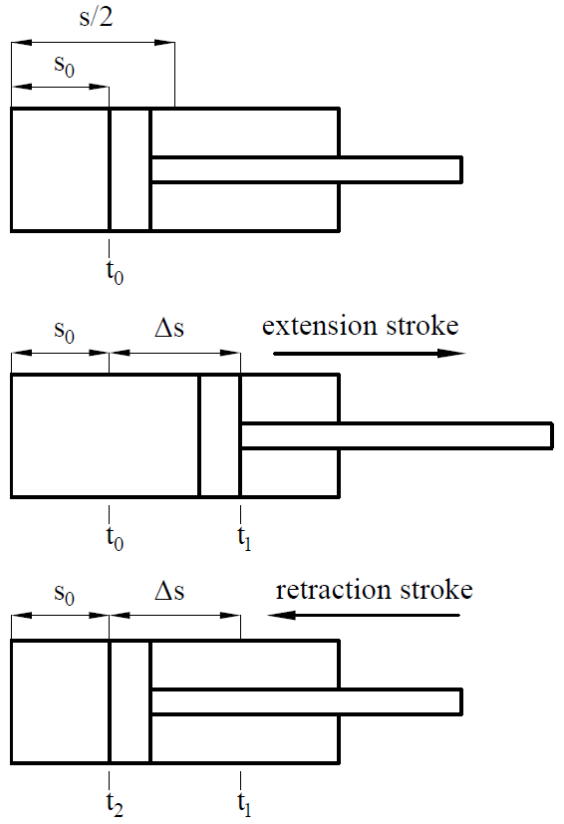

Figure 6: Schematic of a piston movement during the testes with indication of the important parameters

The test stand is operated on the hydraulic oil Renolin HV46. The parameters of the cylinder and of the power supply lines used in the tests are presented in Table 1.

Table 1: Parameters of the cylinder

\begin{tabular}{ll}
\hline Cylinder parameter & Value $[\mathrm{mm}]$ \\
\hline Piston diameter, $\mathrm{D}$ & 80 \\
Piston rod diameter, $\mathrm{d}$ & 50 \\
Piston stroke, $\mathrm{s}$ & 495 \\
Supply line length, $\mathrm{l}_{\mathrm{I}}$ & 4930 \\
Supply line length, $\mathrm{1}_{\mathrm{II}}$ & 4370 \\
Supply line length, $\mathrm{1}_{1}=\mathrm{l}_{2}=\mathrm{l}_{3}=\mathrm{l}_{4}$ & 70 \\
$\begin{array}{l}\text { Hose internal diameter, } \\
\mathrm{d}_{1}=\mathrm{d}_{2}=\mathrm{d}_{3}=\mathrm{d}_{4}=\mathrm{d}_{\mathrm{I}}=\mathrm{d}_{\mathrm{II}}\end{array}$ & 12.7 \\
\hline
\end{tabular}

In order to obtain two liquid domains having considerably different temperatures both in the hydraulic system of the test stand and in the actual cylinder equipped with the new power supply system, hydraulic bypass lines were designed (Figures 7 and 8). It should be emphasized that the four-way, three-position directional valve (4) visible in the diagrams is 
used for controlling only in the case of testing the classic solution. In the case of tests of the new solution, its position is unchanged and provides only power supply to the cylinder. Motion control is carried out by means of two-way two-position valves (6) mounted on the cylinder, controlled in pairs. The spool valve in the system was left deliberately in order not to introduce geometric changes in the compared systems. As a result, it was possible to use a throttle valve to heat the liquid in the bypass without the need for piston movement. After the liquid had been heated, valve settings were modified and the tests were started. The heated liquid was in the hydraulic power supply lines, while the liquid present in the cylinder and in the supply system directly linked to this cylinder had a considerably lower temperature. A test of such design allowed observations of the liquid mixing phenomenon during cylinder movement, as well as comparative tests for cylinders with the classic and with the new power supply system. During the tests here described, the liquid in the parallel circuits was always heated to the same initial temperature equal to $55^{\circ} \mathrm{C}$. This was followed by closing the parallel circuits and initiating the process of supplying the investigated cylinder with heated liquid. Importantly, during the tests of the cylinder supply according to the new design, the temperature of liquid circulating in the system, as measured with a temperature transducer located on the return line (T5), stabilized at $48^{\circ} \mathrm{C}$, while in the case of the classic solution, this temperature was approximately $45^{\circ} \mathrm{C}$. This difference was due to different oil volumes originally present in the system of cylinder chambers and power supply lines. The initial temperature of this oil was always $21^{\circ} \mathrm{C}$. The constant initial temperature of the cool oil was set when the power lines and the cylinder were subjected to preliminary flushing. As part of test preparations, the piston was also set to its initial position, as predefined for each individual test. The tests allowed plotting curves of time versus temperature, as recorded on the nozzles $\left(T_{1}, T_{2}, T_{3}, T_{4}\right)$ during the cyclical movements of the piston. In this article, the analysis was performed for the first five work cycles of the cylinder.

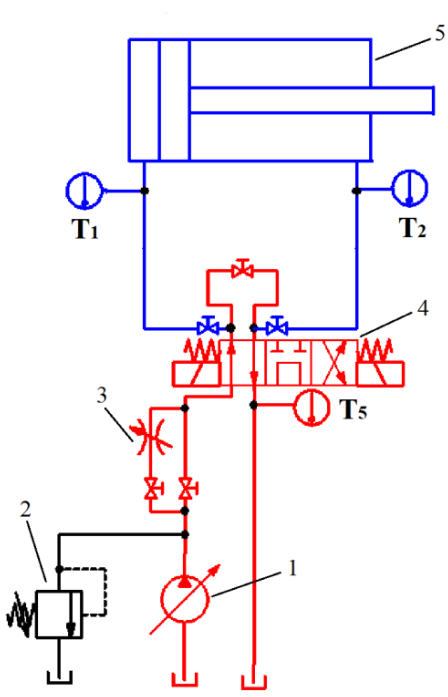

Figure 7: Hydraulic circuit schematic for the standard cylinder test setup: 1 - pump, 2 - pressure relief valve, 3 - choke valve, 4 - directional spool valve, 5 - standard cylinder

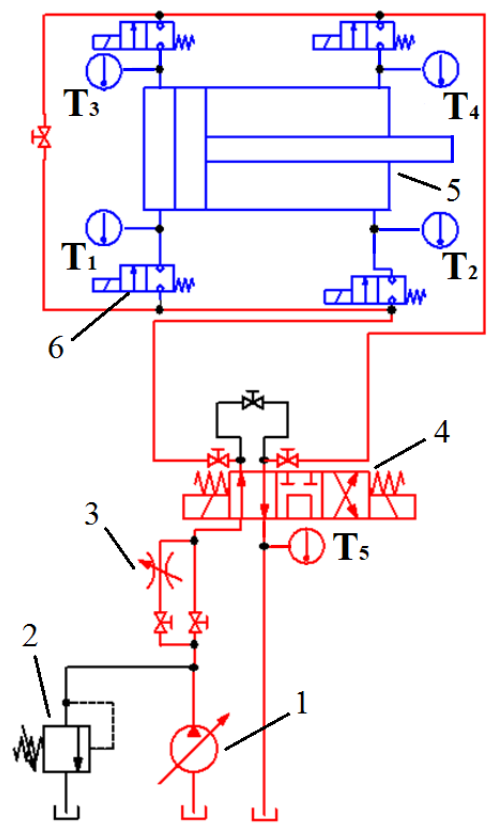

Figure 8: Hydraulic circuit schematic for the new cylinder test setup: 1 - pump, 2 - pressure relief valve, 3 - choke valve, 4 - directional spool valve, 5 - a new cylinder, 6 - control valves 
Comparative tests were performed for the classic and the new cylinder power supply systems with allowance for the change of piston strokes (Table 2).

Table 2: Experimental tests parameters

\begin{tabular}{lccc}
\hline Cylinder & $\mathrm{s}_{0}[\mathrm{~mm}]$ & $\Delta \mathrm{s}[\%]$ & $\Delta \mathrm{s}[\mathrm{mm}]$ \\
\hline Standard & 198.0 & 20 & 99.0 \\
Standard & 148.5 & 40 & 198.0 \\
Standard & 99.0 & 60 & 297.0 \\
Standard & 49.5 & 80 & 396.0 \\
Standard & 0.0 & 100 & 495.0 \\
\hline New & 198.0 & 20 & 99.0 \\
New & 148.5 & 40 & 198.0 \\
New & 99.0 & 60 & 297.0 \\
New & 49.5 & 80 & 396.0 \\
New & 0.0 & 100 & 495.0 \\
\hline
\end{tabular}

\section{TEST RESULTS AND DISCUSSION}

The experimental test results are depicted in Figures 9-12 in the form of curves representing changes of liquid temperature measured in measurement points located on the cylinder $\left(T_{1}\right.$, $\mathrm{T}_{2}, \mathrm{~T}_{3}, \mathrm{~T}_{4}$ ) during the tests of the classic and the new power supply solution. Each plot represents five cycles of piston movement with specified strokes, starting from an extension stroke. The grey vertical lines on the plots show a beginning and an end of each stroke.

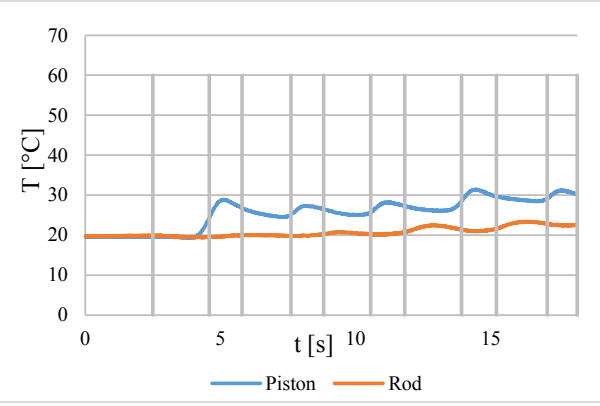

Figure 9: Temperatures measured at the outlets $T_{1}, T_{2}$ in the standard cylinder, $\Delta s=20 \%$

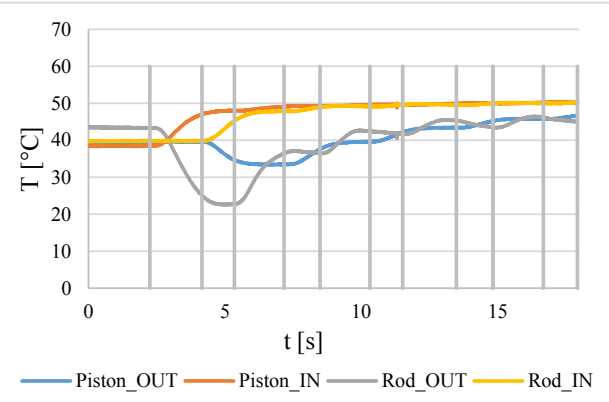

Figure 10: Temperatures measured at the outlets $T_{1}, T_{2}$, $\mathrm{T}_{3}, \mathrm{~T}_{4}$ in the new cylinder, $\Delta \mathrm{s}=20 \%$

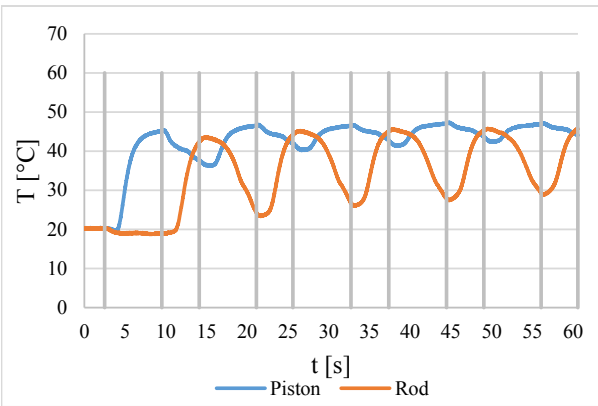

Figure 11: Temperatures measured at the outlets $T_{1}, T_{2}$ in the standard cylinder, $\Delta s=100 \%$

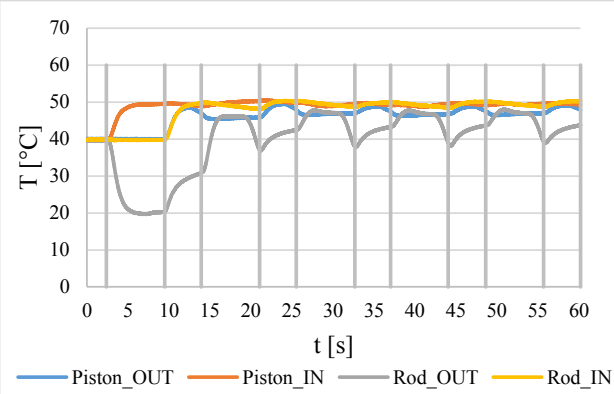

Figure 12: Temperatures measured at the outlets $T_{1}, T_{2}$, $\mathrm{T}_{3}, \mathrm{~T}_{4}$ in the new cylinder, $\Delta \mathrm{s}=100 \%$

As the tests were planned in such a manner that the hot oil was supplying cold cylinder system, the presented on the graphs results should be interpreted as: the faster the oil temperature reach stabilized highest value, the better heat dissipation and cylinder chamber flushing. Comparing the tests results for classic and new cylinder design for a small stroke of $20 \%$, it may be seen that in classic design, the temperature of oil does not reach the reference temperature value of about $45^{\circ} \mathrm{C}$ and is not even close, which means 
that the fluid flows between closed volume of lines and cylinder limiting heat dissipation. While in the new solution, even for the small stroke of $20 \%$, the visible fluid circulation may be seen, as the oil temperature reaches the reference value of $48^{\circ} \mathrm{C}$ after only five cycles, both in the piston and piston-rod chamber. Better fluid circulation may be seen in a classic solution for the full stroke in comparison to the smaller strokes, but for the new cylinder design, the heat energy removal is much faster.

In order to analyze the balance of thermal energy during the investigated piston strokes, the amount of thermal energy introduced into the system was assumed to be:

$H_{\text {in }}=\mathrm{c} \cdot T_{\text {in }} \cdot m_{\text {in }}$

The amount of thermal energy discharged from the cylinder may be described with a simplified relationship with allowance for mean value error:

$H_{\text {out }}=\mathrm{c} \cdot T_{\text {av }} \cdot m_{\text {out }}$

As the simulated work cycle of the cylinder consists of the extension and retraction strokes, and as the final position of the piston was identical with its initial position (Figure 6), an assumption may be made that the mass of liquid introduced to the system equals the mass of liquid removed from the system:

$m_{\text {in }}=m_{\text {out }}$

Therefore, the amount of thermal energy removed from the system $(\Delta \mathrm{H})$ during one work cycle is described with the following relationship:

$\Delta H=H_{\text {out }}-H_{\text {in }}=C \cdot\left(T_{a v}-T_{\text {in }}\right)$

where:

$C=c \cdot m_{\text {in }}=c \cdot m_{\text {out }}$

and $\mathrm{C}$ is constant.

The above relationships indicate that mean liquid temperatures measured on the liquid removal lines should be the basic parameter for the comparison of individual solutions aimed at improving the process of removing liquid from the system and exchanging it with new liquid fed from supply lines. The reference temperature was the value of temperature measured at the outlet of the system, after the process of heat exchange has stabilized. Figures 13 - 16 show graphs of mean temperature values as a function of the number of work cycles.

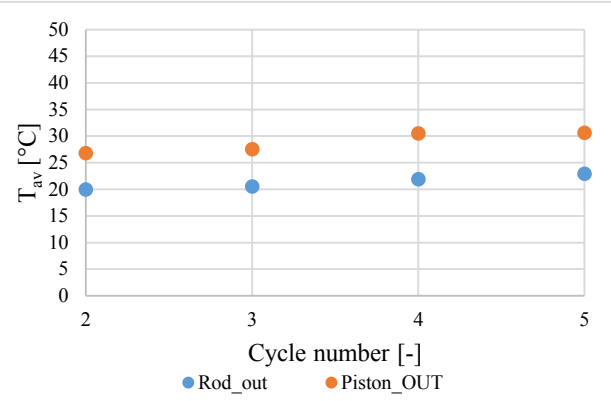

Figure 13: Average temperature values of liquid flowing out from the standard cylinder during each cycle, $\Delta \mathrm{s}=20 \%$

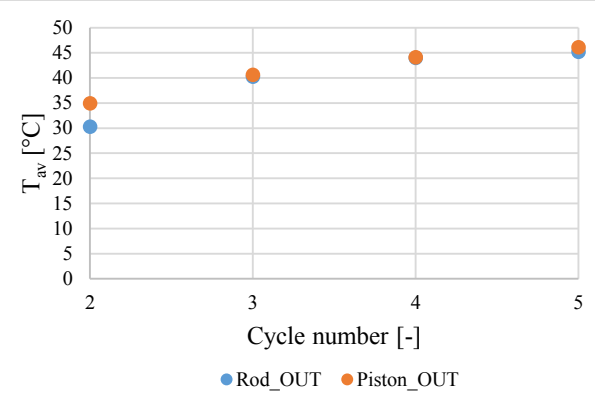

Figure 14: Average temperature values of liquid flowing out from the new cylinder during each cycle, $\Delta s=20 \%$

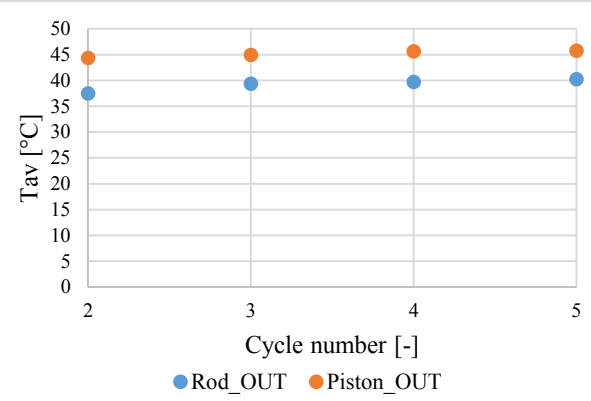

Figure 15: Average temperature values of liquid flowing out from the standard cylinder during each cycle, $\Delta \mathrm{s}=100 \%$ 


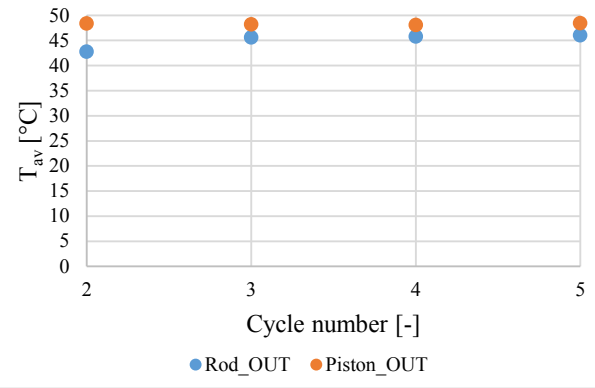

Figure 16: Average temperature values of liquid flowing out from the new cylinder during each cycle, $\Delta s=100 \%$

An interesting observation of such a comparison of the experimental tests results is that for the smallest analyzed stroke, the satisfying heat removal in the new cylinder design may be seen even after only three cycles, and a complete chamber flushing may be obtained after five cycles. During the full stroke of a piston, the complete circulation of oil flow may be seen in the piston chamber after the second cycle. In the piston-rod chamber, the flow circulation is slightly lower because of a piston rod. In the classic cylinder, the high difference of average temperatures may be seen between the piston and piston-rod chambers, which means that in the piston-rod chamber the flow circulation is much lower.

In order to precisely represent the character of the obtained liquid exchange degree for each of the cases, the graphs in Figures 17 - 20 include compared curves of mean temperature changes, as recorded at the outlet for various piston strokes.

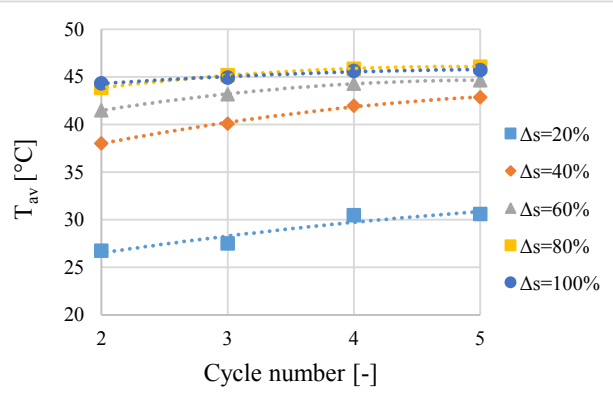

Figure 17: Comparison of average temperature values of liquid flowing out from the piston chamber of the standard cylinder during each cycle for all test cases

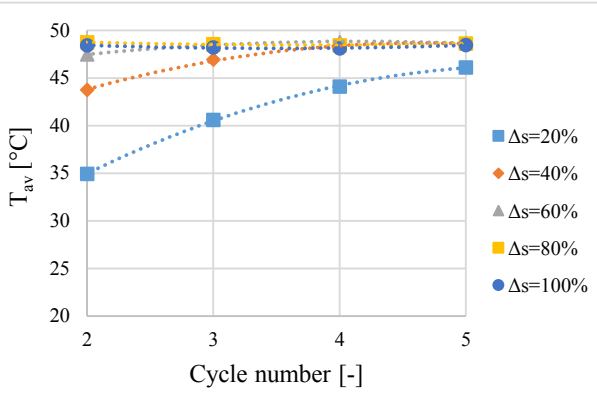

Figure 18: Comparison of average temperature values of liquid flowing out from the piston chamber of the new cylinder during each cycle for all test cases

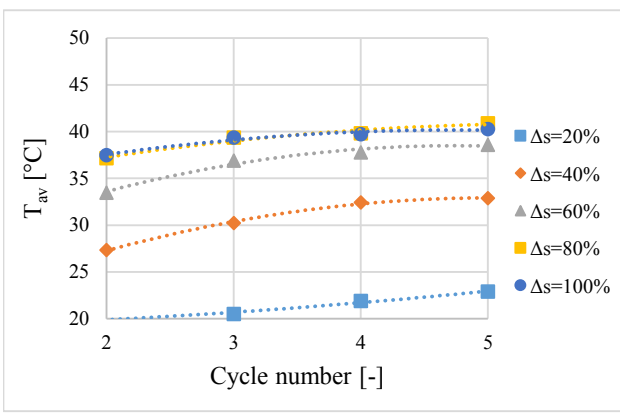

Figure 19: Comparison of average temperature values of liquid flowing out from the piston rod chamber of the standard cylinder during each cycle for all test cases

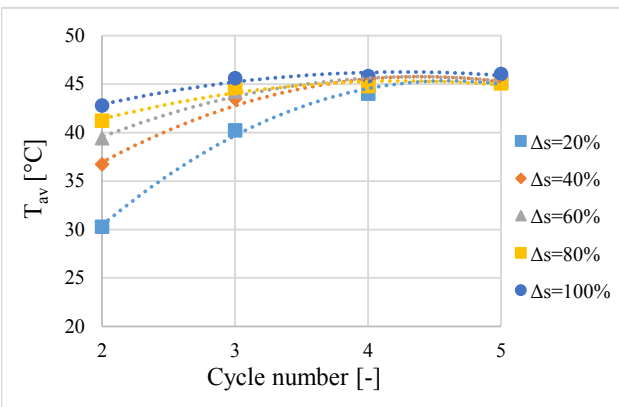

Figure 20: Comparison of average temperature values of liquid flowing out from the piston rod chamber of the new cylinder during each cycle for all test cases

The results clearly indicate that a change in the cylinder power supply method has a significant influence on the liquid exchange degree during different piston strokes. 
Analyzing the fluid exchange process in a piston chamber of a new cylinder design it may be seen that for a $20 \%$ stroke a full circulation of fluid may be obtained after almost 5 cycles, for the $40 \%$ of stroke after almost three cycles, and for the strokes equal or higher than $60 \%$ - after two cycles. For the piston-rod chamber of a new cylinder, the fluid circulation more difficult, but the full fluid exchange is possible for all range of strokes after only five cycles.

\section{CONCLUSION AND OUTLOOK}

Comparative tests of the classic and the new hydraulic cylinder power supply systems provide results which support the theoretical assumptions that the implementation of a new power supply system significantly improves the process of exchanging the liquid supplied to the cylinder with the liquid already present in the cylinder chambers. A particular improvement was achieved in the case when the piston stroke was other than full. The results demonstrate that the new solution allows significantly enhanced thermal energy removal from the chambers of the operating cylinder. Deployment of the new solution especially in machines operated under difficult conditions will provide data on how the modifications influence the actual life of cylinders, and how they will translate into the economic effect. Importantly, the application potential of the test stand developed as part of this project is considerably broader and not limited to the analysis of thermal phenomena. The use of the new solution together with the adapted power supply system, in which the flow resistance will have values comparable to those of the classic architecture system, as shown in the presented test results, will allow the elimination of local thermal energy compensation in the cylinder chambers. Ensuring a significantly higher exchange of liquid in the chambers directly reduces the value of temperatures affecting the seals during operation of heavily operated cylinders and operating at high ambient temperatures. The tests showed the effect of the analyzed phenomenon on the temperatures recorded in the chambers. The results can be used to analyze phenomena occurring in cylinders operated at high ambient temperatures, where the oil temperature values in the cylinders significantly exceed the allowable temperatures for seals, while the oil temperature limit in the tank is not exceeded. In the future it is possible to perform research into the influence of the new solution on the accuracy of piston positioning during the start-up and the braking action. Plans also include comparative tests of the cylinder stiffness parameter in the new and in the classic solutions. Another interesting research area is how the process of liquid mixing is influenced by the shape and the position of the nozzles for supplying liquid to the cylinder chambers.

\section{NOMENCLATURE}

A Piston surface area $\left[\mathrm{mm}^{2}\right]$

c Specific heat of oil $[\mathrm{kJ} / \mathrm{kg} \cdot \mathrm{K}]$

$\mathrm{d}_{1}, 2, \ldots$ Inner diameter of the supply line $[\mathrm{mm}]$

$\mathrm{d} \quad$ Piston rod diameter [mm]

D Piston diameter [mm]

$\mathrm{H}_{\text {in, out }}$ Thermal energy supplied to/removed from the system [J]

$\Delta \mathrm{H} \quad$ Thermal energy removed from the system during one cycle $[\mathrm{J}]$

$1_{1}, 2, \ldots$ Length of the supply line $[\mathrm{m}]$

$\mathrm{m}_{\text {in }}$, out Mass of the liquid supplied to/removed from the system during one working cycle of the cylinder [kg]

s Piston full stroke $[\mathrm{mm}]$

$\mathrm{s}_{0} \quad$ Initial position of the piston [mm]

$\Delta \mathrm{s} \quad$ Piston stroke $[\mathrm{mm}]$

$\mathrm{t}_{0}, 1, \ldots$ Time of start and stop a piston movement $[\mathrm{s}]$

$\mathrm{T}_{1}, 2, \ldots$ Temperature of oil measured during tests $\left[{ }^{\circ} \mathrm{C}\right]$

$\mathrm{T}_{\mathrm{av}} \quad$ Mean temperature of the liquid flowing from the cylinder chamber between time $\mathrm{t}_{1}$ and $\mathrm{t}_{2}$, and further cycles $\left[{ }^{\circ} \mathrm{C}\right]$

$\mathrm{T}_{\text {in }} \quad$ Temperature of the liquid flowing into the cylinder $\left[{ }^{\circ} \mathrm{C}\right]$

$\mathrm{V}_{0} \quad$ Volume of liquid present in the cylinder chamber at a time of initiating a movement $\left[\mathrm{dm}^{3}\right]$

$\mathrm{V}_{\mathrm{c}} \quad$ Initial volume of the cylinder chamber $\left[\mathrm{dm}^{3}\right]$

$\mathrm{V}_{1} \quad$ Volume of the cylinder chamber power supply line $\left[\mathrm{dm}^{3}\right]$

\section{REFERENCES}

[1] Król R, Zimroz R, Stolarczyk Ł. (2009) Failure analysis of hydraulic systems used in mining machines operating in copper ore mine KGHM Polska Miedz S.A. (in Polish). Min Sci; 128:127-39

[2] Stryczek S. (2014) Hydrostatic drive (in Polish) Vol. 1 and 2. Warsaw: WNT

[3] Watton J. (2009) Fundamentals of Fluid Power Control. Cambridge University Press

[4] Siwulski T, Warzyńska U. (2017) The advantages of a new hydraulic cylinder design 
with a control system. In: Vladimír Fuis, editor. Eng. Mech. 2017, Brno University of Technology, Institute of Solid Mechanics, Mechatronics and Biomechanics, Brno; 2017, p. 874-877

[5] Siwulski T, Warzyńska U. (2017) Method of filling and emptying the working chamber of the hydraulic cylinder and a hydraulic cylinder together with a control system and a hydraulic cylinder for performing the method according to the invention. PCT/PL2016/000146 